\title{
Violência obstétrica em mulheres brasileiras
}

\author{
Carolina Coelho Palma \\ Tagma Marina Schneider Donelli \\ Universidade do Vale do Rio dos Sinos, RS, Brasil
}

\section{Resumo}

Esta pesquisa objetivou verificar a ocorrência de violência obstétrica em mulheres brasileiras. Realizou-se um estudo quantitativo, descritivo, transversal, de alcance correlacional e preditivo, utilizando-se o Questionário de Violência no Parto. Os dados foram coletados por acesso online ao questionário. Realizou-se análise descritiva, de correlação e de regressão, através do programa SPSS. Participaram da pesquisa 1626 mulheres adultas. Os resultados apontam que durante o parto 52,3\% das gestantes sentiu-se inferior, vulnerável e insegura; 49,8\% sentiu-se exposta e sem privacidade. A vivência de violência no parto apresentou correlação significativa com idade, escolaridade e renda familiar. Através da análise de regressão múltipla, verificou-se 12 práticas de atendimento ao parto que mostraram-se preditores significativos de violência no parto, explicando 34,9\% da vivência de violência obstétrica. Percebe-se que intervenções desnecessárias são realizadas em nome de uma falsa impressão de que, quanto mais se intervém, mais se cuida.

Palavras-chave: Violência; Parto; Nascimento.

\section{Obstetric violence in Brazilian womans}

\begin{abstract}
The objective of this research was to verify the occurrence of obstetric violence in Brazilian women. It was conducted a quantitative approach, descriptive, cross-sectional and correlational and predictive range design study, using the Birth Violence Questionnaire. The data were collected through online access to the questionnaire and analyzed using SPSS. The participants were 1626 adult women. $52.3 \%$ felt inferior, vulnerable and insecure; $49.8 \%$ felt no privacy. When carrying out the correlation analysis it was found that the violence experience in delivery had a weak negative correlation with age, educational level and family income. Through multiple regression analysis, there were 12 models to obstetric care practices that were significant predictors of violence in childbirth, explaining $34.9 \%$ of the experience of violence in childbirth. Within this panorama, we see the importance and the need to install a genuine process of humanization of labor and birth.
\end{abstract}

Keywords: Violence; Delivery; Childbirth.

\section{Violencia obstétrica en mujeres brasileñas}

\section{Resumen}

Este estudio tuvo como objetivo verificar la ocurrencia de violencia obstétrica en mujeres brasileñas. Se llevó a cabo un estudio de alcance cuantitativo, descriptivo, transversal, correlacional y predictivo, utilizando el Cuestionario de Violencia en el Parto. Los datos fueron recolectados acceso en línea al cuestionario y se analizaron con el programa SPSS. Los participantes fueron 1626 mujeres adultas. 52,3\% se sentía inferior, vulnerable e inseguro; 49.8\% sintió expuesta, sin privacidad. La experiencia de la violencia en el parto tenía una débil correlación negativa con edad, educación y los ingresos familiares. A través del análisis de regresión múltiple, se produjo el parto 12 a las prácticas de cuidado que fueron predictores significativos de la violencia en el parto, que explican el $34,9 \%$ de experiencia de violencia obstétrica. Se observa que las intervenciones innecesarias se llevan a cabo en nombre de una falsa impresión de que cuanto más se interviene y cuidan.

Palabras clave: Violencia; Parto; Nacimiento. 
Na prática obstétrica exercida no Brasil, assim como em outros países, a assistência ao parto é tipicamente organizada como uma linha de montagem, onde a mulher passa por diferentes locais conforme os estágios do seu trabalho de parto, o que acaba por interferir na fisiologia e no desenvolvimento do processo do parto (Diniz, 2001). Além disso, o aumento das intervenções e, consequentemente, das hospitalizações, teve como um de seus resultados o crescimento do número de operações cesarianas desnecessárias. Este aumento, por sua vez, propicia uma maior exposição de mães e bebês a riscos, além de elevar os gastos para o sistema de saúde (Faúndes \& Cecatti, 1991).

Diante desse panorama, a Rede Cegonha, estratégia do Ministério da Saúde, divulgou um conjunto de ações relacionadas às Boas Práticas de Atenção ao Parto e Nascimento, de acordo com a OMS (1996), classificando as práticas comuns na condução do parto normal, orientando para o que deve e o que não deve ser feito no processo do parto. Esta classificação foi baseada em evidências científicas concluídas através de pesquisas feitas no mundo todo. Após discutir as evidências, o grupo de trabalho desenvolveu uma classificação das práticas relacionadas à atenção ao parto (OMS, 1996).

Como práticas úteis e que deveriam ser estimuladas (A), pode-se citar o respeito à escolha da mulher quanto ao acompanhante durante trabalho de parto e parto; contato cutâneo direto precoce entre mãe e filho e apoio ao início da amamentação na primeira hora do pós-parto, entre outras (OMS, 1996). Referente a práticas claramente prejudiciais ou ineficazes e que devem ser eliminadas (B), pode-se citar o uso rotineiro de enema; uso rotineiro de tricotomia; infusão intravenosa de rotina no trabalho de parto; administração de ocitócicos em qualquer momento antes do parto, de um modo que não se permita controlar seus efeitos, entre outras (OMS, 1996).

Em relação às práticas sobre as quais não existem evidências suficientes para apoiar uma recomendação clara e que devem ser utilizadas com cautela, até que mais pesquisas esclareçam a questão (C) ressaltam-se amniotomia precoce no primeiro estágio do trabalho de parto, tração controlada do cordão ou combinação de ambas durante o terceiro estágio do trabalho de parto; clampeamento precoce do cordão umbilical; entre outras (OMS, 1996). E, finalmente, entre as práticas frequentemente utilizadas de modo inadequado (D) estão a restrição hídrica e alimentar durante o trabalho de parto; controle da dor por analgesia peridural; exames vaginais repetidos ou frequentes, especialmente por mais de um prestador de serviços; uso liberal ou rotineiro de episiotomia, entre outras (OMS, 1996).
Dentro deste contexto, foi realizada, em 2010, uma pesquisa empreendida por um grupo de pesquisadores da Universidade de São Paulo (USP), com 2365 mulheres. Os resultados revelaram que $25 \%$ das mulheres entrevistadas sofreram algum tipo de agressão durante o parto. Já 23\% relataram ouvir algum despropósito durante o parto, como "não chora, que ano que vem você está aqui de novo" (Venturini et al., 2010). Dessa forma, pela primeira vez, a violência denominada até então de "institucional" é caracterizada como "violência no parto" e, mais especificamente, como "violência obstétrica", trazendo a público algumas das impressões femininas da atual assistência médico-hospitalar do país (Carneiro, 2013).

É importante ressaltar que no Brasil, ao contrário de países como Argentina (Lei Nacional no 25.929) e Venezuela (Guerra, 2012), ainda não consta na legislação uma lei específica que caracterize a violência obstétrica. Conforme definição da Defensoria Pública do Estado de São Paulo (DPESP, 2013), violência obstétrica caracteriza-se pela apropriação do corpo e dos processos reprodutivos das mulheres pelos profissionais de saúde, através do tratamento desumanizado, abuso da medicalização e patologização dos processos naturais, causando a perda da autonomia e capacidade de decidir livremente sobre seus corpos e sexualidade, impactando negativamente na qualidade de vida das mulheres (DPESP, 2013).

A violência obstétrica pode se caracterizar ainda pela prática de comentários constrangedores à mulher, a fim de ofender, humilhar ou xingar a mulher ou sua família. Negligenciar atendimento de qualidade e agendar cesárea sem recomendação baseada em evidências científicas, atendendo aos interesses e conveniência do médico também são considerados atos de violência obstétrica (DPESP, 2013).

Ainda sobre esta temática, a Organização Mundial da Saúde (2014) divulgou uma declaração intitulada "Prevenção e eliminação de abusos, desrespeito e maus-tratos durante o parto em instituições de saúde". Cabe ressaltar que ainda não há consenso internacional sobre como esses problemas podem ser cientificamente definidos e medidos. Em consequência, sua prevalência e impacto na saúde, no bem-estar e nas escolhas das mulheres não são conhecidos. Segundo a declaração da OMS, ainda são necessárias mais pesquisas científicas para definir, medir e compreender melhor o desrespeito e abusos das mulheres durante o parto, assim como formas de prevenção e eliminação da violência obstétrica (OMS, 2014).

Em recente estudo, Diniz et al. (2015) afirma a necessidade de aprofundamento dos estudos e pesquisas sobre os amplos aspectos relacionados à 
prática de violência obstétrica. Sugere, ainda, analisar em maior profundidade os possíveis impactos sobre a saúde materna e infantil, auxiliando, assim, no desenvolvimento de ações inovadoras na saúde pública brasileira. Assim, o objetivo deste trabalho é verificar aocorrência de Violência Obstétrica em mulheres brasileiras.

\section{Método}

\section{Delineamento}

Esta pesquisa foi realizada de acordo com a metodologia de pesquisa quantitativa, descritiva, transversal e de alcance correlacional e preditivo (Sampieri, Collado, \& Lucio, 2013).

\section{Participantes}

Participaram deste estudo 1626 mulheres, adultas, primíparas ou multíparas, que deram à luz em maternidades públicas ou privadas brasileiras, pertencentes às cinco diferentes regiões do país, que responderam ao Questionário de Avaliação de Violência no Parto. A pesquisa foi divulgada nas principais redes sociais da internet através da publicação do endereço eletrônico que daria acesso ao questionário.

Foram incluídas no estudo apenas as mulheres que concordaram com os termos apresentados no Termo de Consentimento Livre e Esclarecido, o qual foi apresentado previamente ao questionário. Foram excluídas do estudo 71 mulheres pelos seguintes motivos: não concordar em participar da pesquisa, ter menos de 18 anos ou ter tido seu parto em outro país que não o Brasil.

\section{Instrumentos}

A coleta de dados para a realização da pesquisa foi realizada através da utilização do Questionário de Avaliação de Violência no Parto (Online - Anexo 1). Este questionário foi elaborado pela pesquisadora, tendo-se em vista que não existem instrumentos que avaliem a experiência de violência no parto. No questionário constam, inicialmente, os dados sociodemográficos das participantes, tais como região do Brasil onde reside, nível socioeconômico, escolaridade e renda familiar. Em seguida, apresentam-se questões de caráter clínico, referentes ao tipo de parto, local do parto, número de gestações anteriores, se houve algum aborto, complicações durante gestação e/ou parto, preferência pelo tipo de parto e profissional que atendeu ao parto.

Além disso, o instrumento apresenta doze itens referentes a experiências e sentimentos experimentados pelas participantes, os quais auxiliam a caracterizar a vivência de violência obstétrica. Estes itens são apresentados individualmente dentro de uma escala de zero a dez, onde a respondente deve marcar o número correspondente à intensidade de cada vivência, sendo que o número zero indica que a situação não ocorreu. Pode-se, portanto, pontuar um total de 120 pontos, os quais irão traçar a identificação das participantes com maiores ou menores índices de violência no parto.

Por fim, são apresentados 24 itens onde constam procedimentos e condutas praticadas pelos profissionais de saúde que atendem ao parto, as quais caracterizam-se como prática de violência obstétrica. Finalmente, consta uma escala de 1 a 10 onde a participante indica seu grau de satisfação com a equipe de saúde que atendeu seu parto.

\section{Procedimentos Éticos e de Coleta de Dados}

Inicialmente, o projeto de pesquisa foi submetido ao Comitê de Ética em Pesquisa (CEP) da UNISINOS, sendo avaliado de acordo com a Resolução 466/12, a qual visa assegurar os direitos e deveres que dizem respeito aos participantes da pesquisa, à comunidade científica e ao Estado. Após aprovação pelo CEP, segundo Resolução no 182/2014, Projeto no CEP 14/191 de 12/12/2014, a coleta de dados teve início.

O procedimento de coleta de dados deste estudo iniciou-se através de divulgação do questionário da pesquisa, em versão digital, em diversos meios de comunicação, tais como redes sociais e contatos pessoais da pesquisadora, a fim de que se pudesse abranger uma quantidade satisfatória de participantes. Para ter acesso ao questionário online, a participante, deveria, antes, declarar que leu o Termo de Consentimento Livre e Esclarecido (TCLE - Etapa 1) referente à pesquisa, onde constam a apresentação do estudo; indicação da metodologia e as garantias de privacidade e esclarecimentos decorrentes da pesquisa.

Os dados foram coletados dentro do período de três meses. Após este tempo, os demais questionários preenchidos não foram utilizados para esta pesquisa, sendo armazenados para possíveis futuros estudos.

\section{Análise de Dados}

Os dados foram analisados através do Statistical Package for Social Sciences - SPSS, versão 20.0. A análise descritiva dos dados (Tabelas 1, 2 e 3) contemplou frequências, porcentagem, média, mediana e desvio padrão da amostra. Já a análise de correlação (Tabela 4) foi realizada através da correlação de Pearson entre a variável Vivência de Violência no Parto e as variáveis Idade, Escolaridade e Renda Familiar.

Para realizar a análise de regressão (Tabela 5), o método Stepwise foi o escolhido por este se tratar de um estudo exploratório, onde o relacionamento entre 
as variáveis é pouco conhecido. Assim, foram gerados doze modelos, todos significativos, sendo que o $12^{\mathrm{O}}$ explica 34,9\% da variância, sendo assim, selecionado para a análise.

\section{Resultados}

Responderam ao questionário de Violência no Parto 1626 mulheres brasileiras, primíparas ou multíparas, com idade superior a 18 anos e que concordaram com os termos de participação desta pesquisa. Dentre as características das participantes que constam na Tabela 1, pode-se destacar que a média de idade das mesmas foi de 31,16 (DP=7,16) anos, sendo a maioria da região Sul do Brasil (51,1\%). Foi expressivo o número de participantes com ensino superior e pósgraduação $(62,7 \%)$, sendo que $65,5 \%(n=1065)$ possui renda mensal familiar superior a três salários mínimos. Cabe ressaltar que a preferência por realizar cesárea aumentou, quando comparado o período do início e do final da gestação. Além disso, nesta amostra, 51,6\% $(\mathrm{n}=856)$ das respondentes realizaram cesárea. O maior número dos nascimentos ocorreu em hospital privado, sendo a maioria dos partos vaginais atendido por médico obstetra. Importante ressaltar que a ampla maioria das participantes não teve complicações durante a gestação $(72,2 \%)$ e durante o parto $(79,4 \%)$, conforme verifica-se na Tabela 1.

Em relação às experiências e sentimentos vivenciados pelas participantes durante o atendimento recebido pelos profissionais de saúde em seus partos, pode-se destacar que $52,3 \%(\mathrm{n}=850)$ sentiu-se inferior, vulnerável e insegura; 49,8\% $(n=810)$ sentiu-se exposta e sem privacidade; $42,2 \%(n=686)$ sentiu-se pouco a vontade para fazer perguntas porque não respondiam ou respondiam mal. A Tabela 2 apresenta, ainda, um amplo espectro de experiências e sentimentos vivenciados pelas participantes durante o atendimento ao seu parto ou cesárea.

No que diz respeito aos procedimentos e condutas praticadas pelos profissionais de saúde que atendem ao parto, as quais se caracterizam como prática de violência obstétrica, destacam-se as seguintes práticas: $29,7 \%(n=483)$ teve o contato com seu bebê adiado, para que o profissional realizasse procedimentos desnecessários ou que poderiam esperar; $29,0 \%$ $(\mathrm{n}=337)$ teve corte imediato do cordão umbilical; $27,7 \%(\mathrm{n}=450)$ teve seu bebê levado imediatamente para a sala de procedimentos, sem que nenhum profissional the explicasse o que estava acontecendo com ele; impediram 26,8\% $(n=435)$ de amamentar ou dificultaram o aleitamento na 1 a hora de vida do bebê, sem motivos para justificar esta atitude. Demais procedimentos e condutas realizados sem explicação ou arbitrariamente, segundo a percepção das participantes, podem ser verificados na Tabela 3.

TABELA 1

Dados clínicos e sociodemográficos

\begin{tabular}{|c|c|c|}
\hline Variável & $n$ & $\%$ \\
\hline $\begin{array}{l}\text { Região do Brasil } \\
\text { Norte } \\
\text { Nordeste } \\
\text { Centro Oeste } \\
\text { Sudeste } \\
\text { Sul }\end{array}$ & $\begin{array}{r}62 \\
149 \\
131 \\
452 \\
830\end{array}$ & $\begin{array}{r}3,8 \\
9,2 \\
8,1 \\
27,8 \\
51,1\end{array}$ \\
\hline $\begin{array}{l}\text { Escolaridade } \\
\text { Ensino Fundamental Incompleto } \\
\text { Ensino Fundamental Completo } \\
\text { Ensino Médio Incompleto } \\
\text { Ensino Médio Completo } \\
\text { Ensino Superior Incompleto } \\
\text { Ensino Superior Completo } \\
\text { Pós-Graduação }\end{array}$ & $\begin{array}{r}8 \\
17 \\
44 \\
211 \\
326 \\
449 \\
571\end{array}$ & $\begin{array}{r}0,5 \\
1,0 \\
2,7 \\
13,0 \\
20,0 \\
27,6 \\
35,1\end{array}$ \\
\hline $\begin{array}{l}\text { Renda Familiar } \\
\mathrm{R} \$ 0,00 \text { a } \mathrm{R} \$ 1.500,00 \\
\mathrm{R} \$ 1.501,00 \text { a } \mathrm{R} \$ 3.000,00 \\
\mathrm{R} \$ 3.001,00 \text { a } \mathrm{R} \$ 5.000,00 \\
\mathrm{R} \$ 5.001,00 \text { a } \mathrm{R} \$ 10.000,00 \\
\text { Acima de } 10.000,00\end{array}$ & $\begin{array}{l}170 \\
373 \\
374 \\
435 \\
220\end{array}$ & $\begin{array}{l}10,8 \\
23,7 \\
23,8 \\
27,7 \\
14,0\end{array}$ \\
\hline $\begin{array}{l}\text { Tipo de Parto } \\
\text { Normal } \\
\text { Cesárea }\end{array}$ & $\begin{array}{l}770 \\
856\end{array}$ & $\begin{array}{l}48,4 \\
51,6\end{array}$ \\
\hline $\begin{array}{l}\text { Preferência no início da gestação } \\
\text { Parto normal } \\
\text { Cesárea }\end{array}$ & $\begin{array}{r}1379 \\
246\end{array}$ & $\begin{array}{l}84,9 \\
15,1\end{array}$ \\
\hline $\begin{array}{l}\text { Preferência no final da gestação } \\
\text { Parto normal } \\
\text { Cesárea }\end{array}$ & $\begin{array}{r}1255 \\
370\end{array}$ & $\begin{array}{l}77,2 \\
22,8\end{array}$ \\
\hline $\begin{array}{l}\text { Local do parto } \\
\text { Hospital Público } \\
\text { Hospital Privado } \\
\text { Domicílio } \\
\text { Outro }\end{array}$ & $\begin{array}{r}544 \\
992 \\
65 \\
24\end{array}$ & $\begin{array}{r}33,5 \\
61,0 \\
4,0 \\
1,5\end{array}$ \\
\hline $\begin{array}{l}\text { Profissional que atendeu o parto } \\
\text { Enfermeiro Obstetra } \\
\text { Médico Obstetra } \\
\text { Obstetriz } \\
\text { Parteira } \\
\text { Não sabe/não lembra }\end{array}$ & $\begin{array}{r}150 \\
674 \\
8 \\
13 \\
35\end{array}$ & $\begin{array}{r}17,0 \\
76,6 \\
0,9 \\
1,5 \\
4,0\end{array}$ \\
\hline $\begin{array}{l}\text { Número de gestações anteriores } \\
0 \\
1 \\
2 \\
3 \\
4\end{array}$ & $\begin{array}{r}600 \\
696 \\
224 \\
71 \\
19\end{array}$ & $\begin{array}{r}137 \\
42,9 \\
13,8 \\
4,4 \\
1,2\end{array}$ \\
\hline $\begin{array}{l}\text { Complicações na gestação } \\
\text { Não } \\
\text { Sim }\end{array}$ & $\begin{array}{r}1060 \\
409\end{array}$ & $\begin{array}{l}72,2 \\
27,8\end{array}$ \\
\hline $\begin{array}{l}\text { Complicações no parto/cesárea } \\
\text { Não } \\
\text { Sim }\end{array}$ & $\begin{array}{r}1123 \\
292\end{array}$ & $\begin{array}{l}79,4 \\
20,6\end{array}$ \\
\hline
\end{tabular}


TABELA 2

Experiências e Sentimentos vivenciados no parto/cesárea

\begin{tabular}{lcc}
\hline \multicolumn{1}{c}{ Variável } & $n$ & $\%$ \\
Sentiu-se inferior, vulnerável, insegura & 850 & 52,3 \\
Sentiu-se exposta, sem privacidade & 810 & 49,8 \\
$\begin{array}{l}\text { Sentiu-se pouco a vontade para fazer perguntas } \\
\text { porque não respondiam ou respondiam mal }\end{array}$ & 686 & 42,2 \\
$\begin{array}{l}\text { Sentiu-se ameaçada pela atitude ou fala de algum } \\
\text { profissional }\end{array}$ & 561 & 34,5 \\
Fizeram comentários irônicos em tom de deboche & 465 & 28,6 \\
Criticaram você por seus lamentos ou choros de dor & 411 & 25,3 \\
Impediram a presença de acompanhante & 399 & 24,5 \\
Fizeram piada sobre o seu comportamento & 396 & 24,3 \\
Ameaçaram você & 329 & 20,2 \\
Mandaram você parar de gritar & 243 & 15,0 \\
Gritaram com você & 236 & 14,5 \\
Chamaram você por apelido desagradável & 146 & 9,0 \\
\hline
\end{tabular}

TABELA 3

Procedimentos realizados durante parto/cesárea

\begin{tabular}{|c|c|c|}
\hline Variável & $n$ & $\%$ \\
\hline $\begin{array}{l}\text { Teve o contato com seu bebê adiado, para que o } \\
\text { profissional realizasse procedimentos desnecessários } \\
\text { ou que poderiam esperar }\end{array}$ & 483 & 29,7 \\
\hline Corte imediato do cordão umbilical & 471 & 29,0 \\
\hline $\begin{array}{l}\text { Teve seu bebê levado imediatamente para a sala de } \\
\text { procedimentos, sem que nenhum profissional lhe } \\
\text { explicasse o que estava acontecendo com ele }\end{array}$ & 450 & 27,7 \\
\hline $\begin{array}{l}\text { Impediram ou dificultaram o aleitamento na } 1^{\text {a }} \text { hora de } \\
\text { vida do bebê, sem motivos para justificar esta atitude }\end{array}$ & 435 & 26,8 \\
\hline $\begin{array}{l}\text { Começar a cortar seu abdômen, sem esperar a } \\
\text { anestesia "fazer efeito" }\end{array}$ & 393 & 24,2 \\
\hline Toques vaginais realizados por diferentes pessoas & 386 & 23,8 \\
\hline Ocitocina sintética & 341 & 21,0 \\
\hline Toques vaginais repetitivos & 338 & 20,8 \\
\hline Episiotomia & 337 & 20,7 \\
\hline Teve "puxos dirigidos" pelo profissional de saúde & 334 & 20,6 \\
\hline $\begin{array}{l}\text { Manter suas mãos amarradas, impedindo que tocasse } \\
\text { seu bebê }\end{array}$ & 303 & 18,6 \\
\hline $\begin{array}{l}\text { Foi impossibilitada de procurar posições mais } \\
\text { confortáveis segundo suas necessidades }\end{array}$ & 278 & 17,1 \\
\hline $\begin{array}{l}\text { Foi privada da possibilidade de adotar a postura mais } \\
\text { confortável para você realizar os puxos }\end{array}$ & 277 & 17,0 \\
\hline Proibição para ingerir alimentos ou bebidas & 267 & 16,4 \\
\hline Rompimento artificial da bolsa & 267 & 16,4 \\
\hline $\begin{array}{l}\text { Foi impossibilitada de caminhar durante o trabalho } \\
\text { de parto }\end{array}$ & 245 & 15,1 \\
\hline Manobra de Kristeller & 228 & 14,0 \\
\hline $\begin{array}{l}\text { Realização de procedimentos sem seu consentimento } \\
\text { ou sem explicar por que eram necessários }\end{array}$ & 208 & 12,8 \\
\hline Tricotomia & 147 & 9,0 \\
\hline Enema & 92 & 5,7 \\
\hline $\begin{array}{l}\text { Conversas paralelas entre os profissionais sobre } \\
\text { outros assuntos }\end{array}$ & 41 & 2,5 \\
\hline $\begin{array}{l}\text { Foi forçada a amamentar ou estabelecer contato com } \\
\text { o contra a sua vontade }\end{array}$ & 38 & 2,3 \\
\hline
\end{tabular}

Ao realizar-se a análise correlacional (Tabela 4) verificou-se que a vivência de violência no parto apresentou correlação significativa fraca negativa com a idade $(\mathrm{r}=-0,131 ; p=0,00)$, escolaridade $(\mathrm{r}=-0,160$; $p=0,00)$ e renda familiar $(\mathrm{r}=-0,244 ; p=0,00)$, indicando que quanto menor a idade, escolaridade e renda familiar das participantes, maior a pontuação no questionário de violência no parto.

TABELA 4

Correlação entre Vivência de Violência no Parto e Idade, Escolaridade e Renda familiar

\begin{tabular}{lccc}
\hline \multicolumn{1}{c}{ Variáveis do modelo } & Correlação de Pearson & $p$ & $n$ \\
\hline Idade & $-0,131^{*}$ & 0,000 & 1626 \\
Escolaridade & $-0,160^{*}$ & 0,000 & 1626 \\
Renda Familiar & $-0,244^{*}$ & 0,000 & 1626 \\
\hline
\end{tabular}

* A correlação é significativa no nível 0,01 .

Através da análise de regressão múltipla (método Stepwise), verificou-se que as variáveis constantes adiante, na Tabela 5, mostraram-se preditores significativos e positivos da vivência de violência no parto, à exceção da realização de Enema, a qual foi a única variável que foi um preditor negativo para vivência de violência no parto. Tal procedimento forneceu um coeficiente de variância explicada (R2) de 0,349, o que determina que as variáveis independentes selecionadas explicaram $34,9 \%$ da vivência de violência no parto.

\section{Discussão}

Grande parte dos dados colhidos nesta pesquisa, em muitos fatores, se assemelharam aos resultados da pesquisa "Nascer no Brasil: Inquérito Nacional sobre Parto e Nascimento", realizada em 2012, que abrangeu 23.894 mulheres, em maternidades brasileiras públicas e privadas, com o objetivo de conhecer os determinantes, a magnitude e os efeitos de intervenções obstétricas no parto. Neste estudo, a taxa de realização de cesáreas entre as participantes foi de 51,6\%, sendo que na referida pesquisa foi de $52 \%$. Cabe lembrar que, segundo a OMS (2015), taxas de cesárea maiores que $10 \%$ não estão associadas com redução de mortalidade materna e neonatal.

Outra questão interessante a ser apontada é que a maior parte das participantes deste estudo possui alto nível de escolaridade e teve acesso a hospital privado. Tais dados apontam para uma contradição entre a possibilidade de acesso a melhores práticas de atenção em classes econômicas melhor favorecidas e o alto índice de cesárea e intervenções nos nascimentos. 
TABELA 5

Variáveis preditoras de vivência de violência no parto

\begin{tabular}{|c|c|c|c|c|c|}
\hline \multirow[t]{2}{*}{ Variáveis do modelo } & \multirow{2}{*}{$\begin{array}{c}\text { Coeficientes } \\
\text { não } \\
\text { padronizados } \\
\text { B }\end{array}$} & \multirow{2}{*}{$\begin{array}{l}\text { Modelo } \\
\text { Padrão }\end{array}$} & \multicolumn{2}{|c|}{$\begin{array}{l}\text { Coeficientes } \\
\text { Padronizados }\end{array}$} & \multirow[t]{2}{*}{$p$} \\
\hline & & & Beta & $T$ & \\
\hline Toques vaginais repetitivos & 6,556 & 1,681 & 0,105 & 3,901 & 0,000 \\
\hline $\begin{array}{l}\text { Teve seu bebê levado imediatamente para a sala de de procedimentos, sem que nenhum } \\
\text { profissional lhe explicasse o que estava acontecendo com ele }\end{array}$ & 11,468 & 1,239 & 0,203 & 9,259 & 0,000 \\
\hline $\begin{array}{l}\text { Impediram ou dificultaram o aleitamento na } 1^{1 \stackrel{a}{ }} \text { hora de vida do bebê, sem motivos para } \\
\text { justificar esta atitude }\end{array}$ & 6,646 & 1,304 & 0,116 & 5,097 & 0,000 \\
\hline Proibição para ingerir alimentos ou bebidas & 6,839 & 1,444 & 0,115 & 4,735 & 0,000 \\
\hline Foi privada da possibilidade de adotar a postura mais confortável para você realizar os puxos & 9,097 & 1,660 & 0,135 & 5,480 & 0,000 \\
\hline Realização de procedimentos sem seu consentimento ou sem explicar por que eram necessários & 9,280 & 1,854 & 0,122 & 5,006 & 0,000 \\
\hline Toques vaginais realizados por diferentes pessoas & 7,452 & 1,731 & 0,109 & 4,305 & 0,000 \\
\hline Teve "puxos dirigidos" pelo profissional de saúde & 6,484 & 1,561 & 0,103 & 4,154 & 0,000 \\
\hline Manter suas mãos amarradas, impedindo que tocasse seu bebê & 6,059 & 1,578 & 0,093 & 3,839 & 0,000 \\
\hline Enema & $-7,197$ & 2,302 & $-0,066$ & $-3,127$ & 0,002 \\
\hline Foi forçada a amamentar ou estabelecer contato com o bebê contra a sua vontade & 8,058 & 3,398 & 0,048 & 2,372 & 0,018 \\
\hline Manobra de Kristeller & 3,307 & 1,630 & 0,045 & 2,029 & 0,043 \\
\hline
\end{tabular}

$\mathrm{R}=0,591 ; \mathrm{R} 2=0,349 ; \mathrm{R} 2$ ajustado=0,344.

Além disso, apenas 17\% dos partos foram atendidos por enfermeiros obstetras, sendo que a ampla maioria dos nascimentos foi atendida por médico obstetra. Este percentual corrobora os números encontrados na Pesquisa Nascer no Brasil (2012), onde apenas 15\% dos nascimentos foram assistidos por enfermeiras e obstetrizes, frequentemente em regiões mais pobres onde há carência de médicos. Ressalta-se que partos vaginais atendidos por esses profissionais tendem a ter menos intervenções desnecessárias, comprometendo menos a saúde das mulheres e seus bebês (Leal et al., 2012).

Da mesma forma como verificado no estudo em comparação, nesta pesquisa verificou-se que diminuiu o desejo pelo parto vaginal ao longo da gestação, o que sugere que a orientação no pré-natal pode estar induzindo a maior aceitação da cesárea Sendo assim, deve-se questionar como está sendo realizada esta orientação, principalmente, em consultórios médicos privados, onde, sabe-se, existe uma série de fatores envolvidos na preferência do profissional pela cesárea, tais como questões de custo e de tempo.

Cabe ressaltar que, nesta pesquisa, o uso de intervenções no parto foi muito elevado, mesmo em gestantes e bebês de baixo risco, o que, nesta circunstância, seria outra contradição existente na assistência prestada pelos profissionais de saúde que estudo aponta. Neste caso, cabe refletir que, em partos e gestações de baixo risco, deveria haver um maior número de atendimentos realizados por enfermeiros obstetras, o que, por consequência, aumentaria a probabilidade de haver um menor número de intervenções.

Através desta pesquisa foi possível verificar que mulheres de baixa escolaridade, renda e nível socioeconômico tendem a sofrer maior violência obstétrica. Estes dados reforçam o fato de que mulheres com este perfil socioeconômico, encontram-se mais socialmente vulneráveis quando comparadas às de classe socioeconômica maior.

Como ressaltado anteriormente, a definição de violência obstétrica ainda é um conceito muito recente e que se encontra em construção entre os profissionais de saúde e estudiosos do tema. Sendo assim, como ainda não existem instrumentos para avaliar esta prática, este questionário foi elaborado na tentativa de auxiliar na caracterização e identificação da violência obstétrica. Para tanto, o mesmo procurou abarcar uma série de sentimentos, experiências e procedimentos que caracterizam a prática de violência obstétrica. Esta caracterização entra em acordo com estudos atuais que vem sendo desenvolvidos por pesquisadores desta área, tais como Tesser et al. (2015) o qual sugeriu que se divida a violência obstétrica nas seguintes categorias: abuso físico; imposição de intervenções não consentidas; intervenções aceitas com base em informações parciais ou distorcidas; cuidado não confidencial ou privativo; cuidado indigno e abuso verbal; discriminação baseada em certos atributos; abandono, negligência ou recusa de assistência e detenção nos serviços de saúde. 
Além disso, este estudo se propôs a verificar quais seriam as intervenções na assistência ao parto que poderiam predizer a sensação de ter vivenciado violência obstétrica entre as participantes desta pesquisa. Assim, como elucidado anteriormente, a análise de regressão realizada apontou para a existência de doze procedimentos, os quais teriam um maior potencial preditivo para a vivência de violência no parto. Pretende-se, a seguir, discutir cada um deles, para melhor entender seu valor preditivo.

A realização de toques vaginais repetidos e realizados por diferentes pessoas apresentou-se como preditor para a vivência de violência no parto. Assim, além deste procedimento potencializar a sensação de dor na mulher, muitas vezes, por ser realizado sem esclarecimentos ou seu consentimento, acaba por aumentar sua sensação de submissão e vulnerabilidade. Muitas vezes, esta intervenção é realizada sem preservar a privacidade da mulher, deixando-a exposta à vista de outros profissionais e até mesmo outros familiares, que muitas vezes, estão no mesmo ambiente, como acompanhantes de outras parturientes.

Outra questão muito comum relatada pelas usuárias é que, em muitos casos, o exame de toque, assim como outros procedimentos, tem como objetivo ensinar os profissionais em formação. Neste caso, além de ser realizado em maior número de vezes, meramente em caráter de ensino, muitas vezes, enquanto realizam o procedimento, o profissional e seus alunos conversam paralelamente sobre as questões técnicas e suas dúvidas, deixando a parturiente à parte, impedindo que se manifeste de maneira que possa lhes interromper ou atrapalhar o aprendizado.

Segundo Rego et al., (2008) no ensino da medicina e demais profissões da saúde, o paciente tende a ser desumanizado, anulado em sua identidade e transformado em um número da ficha hospitalar, em um caso a ser estudado, diagnosticado e tratado. O conjunto da educação dos profissionais tem sido alvo de críticas pela dificuldade de prepará-los com formação humanista. Assim, a relação deixa de ser entre humanos e passa a ser uma relação sujeito-objeto, do médico com a doença (Diniz et al., 2015).

Outro fator apontado como preditor para a vivência de violência no parto foi a separação entre a mãe e seu bebê logo após o nascimento, sem que nenhum profissional the explicasse o que estava acontecendo com ele, ou através do impedimento ou postergação do aleitamento na $1^{\underline{a}}$ hora de vida do bebê, sem motivos para justificar esta atitude.Apesar do Programa Nacional de Incentivo ao Aleitamento Materno (Monson, 1991) ser bastante difundido, muitos serviços não respeitam o desejo da mãe em amamentar seu bebê logo ao nascer, mesmo que não haja nenhum impeditivo clínico para isso. Em algumas maternidades, só é permitido que a mãe permaneça em alojamento conjunto com seu bebê várias horas após o nascimento, ainda que não haja nenhum motivo que justifique a separação mãe-bebê. Essa demora dificulta o início da amamentação e afeta a duração do aleitamento materno exclusivo.

Durante a cesárea, é comum as mulheres terem suas mãos amarradas para a realização do procedimento e mesmo após o nascimento do bebê, o que lhes impede de tocar ou segurar o mesmo. Neste estudo, esta prática foi apontada como mais um dos preditores da vivência de violência no parto. Segundo Salgado, Niy e Diniz (2013), em seu estudo com mulheres que foram submetidas a cesáreas, amarrar os braços das mulheres durante a cirurgia constitui um dos protocolos hospitalares que foi compreendido por várias mulheres como violência obstétrica. Ele é realizado sob a justificativa de evitar que a mulher contamine o campo cirúrgico, porém tal medida não se justifica, muito menos ao final da cesárea, quando as mulheres poderiam ter os braços desamarrados e o contato com seu bebê facilitado. Para além do desconforto físico que é estar com os braços amarrados, há, portanto, uma dimensão simbólica de não poder receber e acolher o seu filho que acaba de nascer.

A proibição para ingerir alimentos ou bebidas ao longo do trabalho de parto consta como outro preditor significativo da vivência de violência no parto. Segundo Singata, Tramer e Gyte (2010), a restrição alimentar e hídrica prolongada pode levar ao desconforto da parturiente. Além disso, há recomendação de que as mulheres tenham liberdade para ingerir líquidos e outros alimentos leves durante o trabalho de parto (OMS, 1996).

Outro fator que apareceu como preditor foi a privação da possibilidade de adotar a postura mais confortável para realizar os puxos. Segundo a OMS (1996), a liberdade de posição e movimento durante o trabalho de parto enquadra-se como prática demonstradamente útil e que deve ser estimulada. Assim, a parturiente deveria ser incentivada a adotar posições diferentes durante o trabalho de parto e fase final do parto, de modo a sentir-se mais confortável, favorecendo a conexão com o próprio corpo, além de facilitar o nascimento.

A realização de procedimentos sem o consentimento da parturiente ou sem explicar por que eram necessários foi um preditor para a vivência de violência no parto. Cabe ressaltar que muitos procedimentos são realizados sem serem informados ou esclarecidos de sua necessidade. Alguns são realizados sem aviso e sem dar a oportunidade da mulher emitir seu consentimento. 
Segundo Ciello et al. (2012) diversos relatos apontam o incômodo em se submeter a exames realizados em seu corpo por pessoas que não se apresentam, não informam a necessidade do exame e realizam comentários agressivos durante o procedimento.

Ter os puxos dirigidos pelos profissionais de saúde foi também um preditor significativo. Sabe-se que o trabalho de parto e o parto são momentos que exigem da mulher grande instrospecção. Assim, a mulher em franco período expulsivo deve-se desligar do mundo e receber o menor número possível de estímulos externos, para que possa, assim, realizar a regressão psíquica necessária para trazer seu bebê ao mundo. No entanto, se os profissionais de saúde e o ambiente em que se encontra impedirem que a mulher faça esta transição de estado físico e mental, a mesma, provavelmente, não terá a oportunidade de sentir-se protagonista do seu processo de parir, sentindo-se insegura, submissa e vulnerável. Neste caso, onde os profissionais dirigem o processo do parto e tiram da mulher este poder, é comum a sensação de que foi o profissional quem "fez o parto" e não a mulher. Neste sentido, pode-se entender a violência obstétrica também como uma forma de violência de gênero, onde as práticas da medicina e o saber médico se sobreõem à autonomia da mulher sobre os saberes acerca de sí mesma.

Da mesma forma como ter o bebê afastado da mãe sem o seu consentimento, forçar a mulher a amamentar ou estabelecer contato com o mesmo também surgiu como preditor da vivência de violência no parto. Sabe-se que há enorme incentivo do governo em relação à prática do aleitamento materno, e sabe-se também que a implementação de programas como o Hospital Amigo da Criança (Brasil, 2008) acaba gerando, muitas vezes, uma cobrança sobre os profissionais. No entanto, estes devem desenvolver uma visão singular de cada mulher que atendem, visto que cada uma que ali chega traz consigo ansiedades, medos, preocupações e demais sentimentos que poderão, em muitos casos, se sobrepor, a comportamentos padrões que espera-se que adotem.

Contrariamente aos demais procedimentos, a prática de Enema, que é a lavagem intestinal realizada no início do trabalho de parto, surgiu como um preditor negativo para vivência de violência no parto. Logo, pode-se inferir que as mulheres que não realizavam este procedimento, sentiam-se, provavelmente, mais expostas, vulneráveis e inseguras. Assim, mesmo que a prática do Enema não seja recomendada pela OMS, seria prudente analisar individualmente cada caso, pois, caso a possibilidade de eliminar fezes seja algo perturbador para a parturiente, esta poderá, inclusive, reprimir-se ou evitar fazer força, pelo medo ou constrangimento frente aos profissionais de saúde. Mais uma vez, cabe aos profissionais ouvir as mulheres, dar voz a elas, reconhecer o seu saber, individualizando e atendendo, assim, às particularidades de cada indivíduo.

A manobra de Kristeller também surgiu como um preditor da vivência de violência no parto, sendo assim, cabe, mais uma vez repensar, por que este procedimento, que há muito tempo não é mais recomendado pela OMS no atendimento ao parto, ainda vem sendo realizado. Pois, além de trazer consequências físicas indesejadas, sabe-se que aumenta ainda mais a sensação da mulher de ter vivido um parto violento. De acordo com Leal et al. (2014), não há evidências sobre o uso da manobra de Kristeller ser benéfico. Os riscos potenciais da realização deste procedimento incluem a ruptura uterina, lesão do esfíncter anal, fraturas em recémnascidos ou dano cerebral, dentre outros.

Faz-se importante ressaltar que, tendo-se em vista que esta pesquisa abrangeu apenas mulheres alfabetizadas e com acesso à internet, deve-se cogitar a possibilidade de que os resultados poderiam ser bastante diferentes dos apresentados, caso esse estudo abrangesse populações rurais, ribeirinhas, quilombolas, do campo e da floresta.

Finalmente, cabe destacar que está havendo uma busca pela caracterização e definição do que é a prática de violência obstétrica, para que se possa identificar e combater a mesma. Sua ocorrência também vem sendo largamente divulgada, afim de que as mulheres possam adotar uma postura de maior protagonismo em seus partos e cesáreas.

\section{Considerações Finais}

A realização deste estudo proporcionou uma ampla visualização dos múltiplos aspectos envolvidos na ocorrência de violência obstétrica em mulheres brasileiras. Através da análise descritiva, correlacional e preditiva das variáveis estudadas, foi possível pensar em possíveis fatores implicados na vivência deste tipo de violência, a qual vem denunciar a necessidade de se repensar sobre as práticas em saúde e a maneira como os profissionais vêm desempenhando suas atividades.

A ampla e rápida aderência das mulheres que se disponibilizaram para responder ao questionário desta pesquisa pode estar relacionada com a crescente necessidade que as mesmas vêm apresentando em denunciar o tema em questão. Além disso, muitas das respondentes manifestaram a necessidade de ajudar a fazer a diferença para que se efetue uma real mudança na maneira como se produz a assistência em saúde no Brasil. Também, muitas se colocaram à disposição para narrar em maior profundidade a violência sofrida 
em seus partos e cesáreas, parecendo demonstrar uma certa necessidade em trazer seus relatos, a fim de problematizar e divulgar o tema.

Apesar de existir uma Política Nacional de Humanização no SUS, através da realização deste trabalho, fica evidente que esta política ainda não foi suficiente para modificar a assistência em saúde no Brasil. É preciso que se pense outras formas mais efetivas para modificar o panorama como os nascimentos vem sendo realizados nas maternidades brasileiras, sejam elas públicas ou privadas.

Especialistas de diversas áreas de atuação relacionadas à saúde vêm apresentando novas possibilidades de intervenção para que se efetive uma mudança na prática obstétrica brasileira. Porém, sabe-se que uma verdadeira mudança envolve aspectos mais amplos, relacionados a uma mudança de paradigma tanto dos profissionais quanto dos usuários do sistema de saúde.

Pode-se pensar que parece estar havendo uma certa incompreensão em relação ao uso das tecnologias em saúde. Intervenções desnecessárias são realizadas em nome de uma falsa impressão de que, quanto mais se intervém, mais se cuida. As próprias mulheres, sob a crença de que seus corpos são falhos e incapazes de gestar ou parir sem uma quantidade imensa de intervenções médicas, muitas vezes acabam clamando por estas intervenções, por acreditarem que não darão conta de parir sozinhas.

No que tange às limitações deste estudo, caberia ressaltar que, tendo-se em vista que o conceito de violência obstétrica encontra-se ainda em construção, deve-se considerar que outras questões poderiam ser somadas às que foram elaboradas para compor $o$ questionário desta pesquisa. Sugere-se que futuros estudos apliquem o questionário de violência no parto em conjunto com outros instrumentos, a fim de avaliar outras questões relacionadas à vivência de violência no parto, tais como depressão pós parto e síndrome de estresse pós traumático.

Por fim, tendo-se em vista que a temática abordada neste estudo ainda encontra-se em construção, acredita-se que muitos estudos ainda são necessários, a fim de aprimorar e tornar mais evidente a importância de qualificar a maneira como os profissionais de saúde atendem o parto e o nascimento no Brasil.

\section{Referências}

Carneiro, R. G. (2013). Dilemas antropológicos de uma agenda de saúde pública: Programa Rede Cegonha, pessoalidade e pluralidade. Interface - Comunicação, Saúde, Educação, 17(44), 49-59. https://doi.org/10.1590/S141432832013000100005

Ciello, C., Carvalho, C., Kondo, C., Delage, D., Niy, D., \& Werner, L. (2012). Parto do princípio. Mulheres em Rede pela Maternidade Ativa. Dossiê da Violência Obstétrica "Parirás com dor". Disponível em: <http://www.senado.gov. br/comissoes/documentos/SSCEPI/DOC\%20VCM\%20367.pdf>. Acesso em: 15 jan. 2016.

Defensoria Pública do Estado de São Paulo. (2013). Violência Obstétrica: você sabe o que é? Núcleo especializado de promoção e defesa dos direitos da mulher e Associação Artemis. Escola da Defensoria Pública do Estado. São Paulo. Disponível em: <http://www.defensoria.sp.gov.br/dpesp/repositorio/41/violencia\%20obstetrica.pdf>. Acesso em: 17 jan. 2016.

Diniz C. S. G. (2001). Entre a técnica e os direitos humanos: possibilidades e limites da humanização da assistência ao parto. Tese de Doutorado. São Paulo: FM/USP.

Diniz, S. G., Salgado, H. D. O., Andrezzo, H. F. D. A., Carvalho, P. G. C. D., Carvalho, P. C. A., Aguiar, C. D. A., \& Niy, D. Y. (2015). Violência obstétrica como questão para a saúde pública no Brasil: origens, definições, tipologia, impactos sobre a saúde materna, e propostas para sua prevenção. Revista brasileira de crescimento e desenvolvimento humano, 25(3), 377-384.

Faúndes, A. \& Cecatti, J. G. (1991). A operação cesárea no Brasil: incidência, tendências, causas, conseqüências e propostas de ação. Cadernos de Saúde Pública, 7(2), 150-173. https://doi.org/10.1590/S0102-311X1991000200003

Guerra, G. B. (2012). Violencia obstétrica. Revista de la Facultad de Medicina, 31(1), 5-6.

Leal, M. D. C., Pereira, A. P. E., Domingues, R. M. S. M., Theme Filha, M. M., Dias, M. A. B., Nakamura-Pereira, M., \& Gama, S. G. N. D. (2014). Intervenções obstétricas durante o trabalho de parto e parto em mulheres brasileiras de risco habitual._https://doi.org/10.1590/0102-311x00151513

Ley Nacional no 25.929 de 17 de septiembre de 2004. Dispões sobre os Derechos de Padres e Hijos durante el Proceso de Nacimiento. Declaración de Interés Del Sistema Nacional de Información Mujer, por parte del Senado de la Nación. Declaración sobre difusión del Parto Humanizado. Câmara de Deputados. Argentina.

Monson, M. R. D. R., Correa, A. M. S., Becker, E. D. A., Witte, E., Almeida, J. A. G. D., Lima Filho, J. B. D., \& Goldenberg, P. (1991). Programa nacional de incentivo ao aleitamento materno: revisão e avaliação das ações nacionais para a implementação dos princípios e objetivos do Código Internacional de comercialização dos substitutos do leite materno. 
Organização Mundial da Saúde. (1996) Assistência ao parto normal: um guia prático. Genebra.

Organização Mundial da Saúde. (2014) Prevenção e eliminação de abusos, desrespeito e maus-tratos durante o parto em instituições de saúde. Disponível em: http://apps.who.int/iris/bitstream/10665/134588/3/WHO_RHR_14.23_por. pdf. Acesso em: 20 jan. 2016.

Organização Mundial da Saúde. (2015). Declaração da Organização Mundial da Saúde sobre as taxas de cesárea. Disponível em: <http://apps.who.int/iris/bitstream/10665/161442/3/WHO_RHR_15.02_por.pdf >. Acesso em: 10 fev. 2016.

Rego, S., Gomes, A. P., \& Siqueira-Batista, R. (2008). Bioética e humanização como temas transversais na formação médica. Rev Bras Educ Med, 32(4), 482-491. https://doi.org/10.1590/S0100-55022008000400011

Salgado, H. D. O, Niy, D. Y., \& Diniz, C. S. G. (2013). Meio grogue e com as mãos amarradas: o primeiro contato com o recém-nascido segundo mulheres que passaram por uma cesárea indesejada. Revista brasileira de crescimento e desenvolvimento humano, 23(2), 190-197.

Sampieri, R. H., Collado, C. F., \& Lucio, M. P. B. (2013). Metodologia de Pesquisa. Porto Alegre: Penso.

Singata, M., Tranmer, J., \& Gyte, G. M. (2010). Restricting oral fluid and food intake during labour. Cochrane Database Syst Rev, 1. https://doi.org/10.1002/14651858.CD003930.pub2

Tesser, C. D., Knobel, R., de Aguiar Andrezzo, H. F., \& Diniz, S. G. (2015). Violência obstétrica e prevenção quaternária: o que é e o que fazer. Revista Brasileira de Medicina de Familia e Comunidade, 10(35), 1-12. https://doi.org/10.5712/ rbmfc10(35)1013

Venturini, G., Bokany, V., \& Dias, R. (2010) Mulheres brasileiras e gênero nos espaços público e privado. São Paulo: Fundação Perseu Abramo/Sesc. Disponível em: <http://novo.fpabramo.org.br/sites/default/files/pesquisaintegra_0. pdf>. Acesso em: 21 jan. 2016.

Zambaldi, C. F., Cantilino, A., \& Sougey, E. B. (2009). Parto traumático e transtorno de estresse pós-traumático: revisão da literatura. J. Bras Psiquiatr, 58(4), 252-257. https://doi.org/10.1590/S0047-20852009000400006

Autores:

Carolina Coelho Palma - Mestre, Universidade do Vale do Rio dos Sinos.

Tagma Marina Schneider Donelli - Doutora, Universidade do Vale do Rio dos Sinos.

Endereço para correspondência:

Carolina Coelho Palma

Rua Dr. Eduardo Chartier, 1151/303

90520100 - Porto Alegre, RS, Brasil

<carolpalms@yahoo.com.br>

Recebido em: 02.09.2016

Aceito em: 18.01.2017 


\section{ANEXO 1 \\ Questionário de Avaliação de Violência no Parto}

Responda ao questionário com base em sua última gestação

\section{Nome completo:}

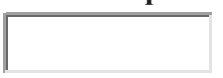

Idade:

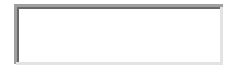

Cidade e Estado onde reside atualmente:

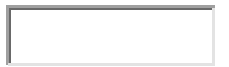

Escolaridade:

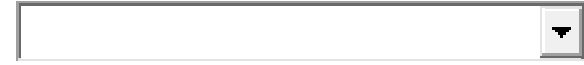

Renda Familiar:

Número de gestações anteriores:

Teve algum aborto?

[C. Sim

E Não

Teve complicações durante a gestação? Se sim, quais?

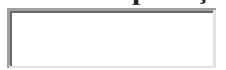

Data do parto:

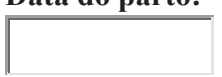

Quantas semanas/dias de gestação ao nascer?

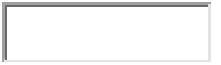

Teve complicações durante o parto/cesárea? Se sim, quais?

1. Que tipo de parto você teve?

C. Normal, sem indução;

Normal, com indução;

Cesárea, após entrar em trabalho de parto;

Cesárea agendada;

Cesárea de emergência.

b Outro.

1.1 Preferência no Início da Gestação:

[. Parto Normal

E. Cesárea

1.2 Preferência no Final da Gestação:

[C Parto Normal

[C Cesárea 
1.3 Se você fez cesariana:

Você DESEJOU A CESARIANA já no início da gestação;

G Você queria PARTO NORMAL, mas mudou de opinião ao longo da gestação, POR VONTADE PRÓPRIA;

C Você queria PARTO NORMAL, mas mudou de opinião ao longo da gestação, POR INDICAÇÃO MÉDICA;

[ Você queria PARTO NORMAL, mas a equipe de saúde fez CESARIANA, mesmo CONTRAA SUA VONTADE;

Outro. Qual?

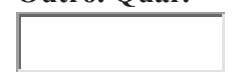

1.4 Se você teve parto normal:

Você DESEJOU O PARTO NORMAL já no início da gestação;

Você queria CESARIANA, mas mudou de opinião ao longo da gestação, POR VONTADE PRÓPRIA;

Você queria CESARIANA, mas mudou de opinião ao longo da gestação, POR INDICAÇÃO MÉDICA;

Você queria CESARIANA, mas a equipe de saúde fez PARTO NORMAL, mesmo CONTRAA SUA VONTADE;

Outro. Qual?

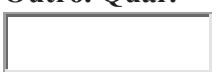

\title{
2. Onde foi seu parto?
}

C. Hospital Público;

Hospital Privado

Domiciliar

$\rightarrow$ Outro.

\subsection{Outro local? Especifique, por favor:}

\author{
2.2 Se você teve parto normal, quem atendeu seu parto? \\ [C Enfermeira(o) Obstetra \\ Médica(o) Obstetra \\ Obstetriz \\ Parteira \\ E Não sabe ou não lembra
}

Durante a internação hospitalar para nascer o seu bebê ou no atendimento domiciliar por equipe de saúde, O QUÃO INTENSAS FORAM ESTAS VIVÊNCIAS COM ALGUM PROFISSIONAL DE SAÚDE:

3. Ele ameaçou você

Assinale a questão, conforme o grau de intensidade do que aconteceu com você, sendo 1 (pouco intenso) e 10 (muito intenso). Caso não tenha vivenciado o que consta na alternativa, marque 0 .

\begin{tabular}{|c|c|c|c|c|c|c|c|c|c|c|c|c|}
\hline & 0 & 1 & 2 & 3 & 4 & 5 & 6 & 7 & 8 & 9 & 10 & \\
\hline Não ocorreu & $B$ & 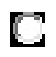 & $\mathrm{C}$ & $B$ & $B$ & 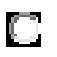 & 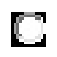 & $E$ & $B$ & 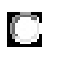 & 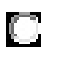 & Muito Intenso \\
\hline
\end{tabular}

\subsection{Gritou com você}

Assinale a questão, conforme o grau de intensidade do que aconteceu com você, sendo 1 (pouco intenso) e 10 (muito intenso). Caso não tenha vivenciado o que consta na alternativa, marque 0 .

\begin{tabular}{|c|c|c|c|c|c|c|c|c|c|c|c|c|}
\hline & 0 & 1 & 2 & 3 & 4 & 5 & 6 & 7 & 8 & 9 & 10 & \\
\hline Não ocorreu & $\mathbb{C}$ & $B$ & 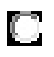 & $\mathrm{C}$ & $\mathrm{C}$ & $\mathbb{B}$ & 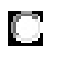 & $\mathrm{C}$ & 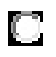 & $\mathbb{b}$ & {[} & Muito Intenso \\
\hline
\end{tabular}

\subsection{Mandou você parar de gritar}

Assinale a questão, conforme o grau de intensidade do que aconteceu com você, sendo 1 (pouco intenso) e 10 (muito intenso). Caso não tenha vivenciado o que consta na alternativa, marque 0 .

\begin{tabular}{|c|c|c|c|c|c|c|c|c|c|c|c|c|}
\hline & 0 & 1 & 2 & 3 & 4 & 5 & 6 & 7 & 8 & 9 & 10 & \\
\hline Não ocorreu & $C$ & 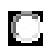 & 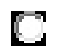 & 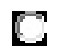 & 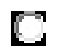 & $\mathrm{C}$ & $B$ & $G$ & $B$ & $B$ & $\mathbb{E}$ & Muito Intenso \\
\hline
\end{tabular}


3.3 Fez piada sobre o seu comportamento

Assinale a questão, conforme o grau de intensidade do que aconteceu com você, sendo 1 (pouco intenso) e 10 (muito intenso). Caso não tenha vivenciado o que consta na alternativa, marque 0 .

\begin{tabular}{|c|c|c|c|c|c|c|c|c|c|c|c|c|}
\hline & 0 & 1 & 2 & 3 & 4 & 5 & 6 & 7 & 8 & 9 & 10 & \\
\hline Não ocorreu & $G$ & $\mathrm{C}$ & $B$ & $G$ & $\mathrm{C}$ & $B$ & $C$ & $\mathrm{~B}$ & $C$ & $\mathrm{C}$ & $\mathbb{E}$ & Muito Intenso \\
\hline
\end{tabular}

3.4 Criticou você por seus lamentos ou choros de dor

Assinale a questão, conforme o grau de intensidade do que aconteceu com você, sendo 1 (pouco intenso) e 10 (muito intenso). Caso não tenha vivenciado o que consta na alternativa, marque 0 .

\begin{tabular}{|l|c|c|c|c|c|c|c|c|c|c|c|c|}
\hline & 0 & 1 & 2 & 3 & 4 & 5 & 6 & 7 & 8 & 9 & 10 & \\
\hline Não ocorreu & $\mathbb{C}$ & $\mathbb{C}$ & $\mathbf{C}$ & $\mathbb{C}$ & $\mathbb{C}$ & $\mathbb{C}$ & $\mathbb{C}$ & $\mathbb{C}$ & $\mathbb{C}$ & $\mathbb{C}$ & $\mathbb{C}$ & Muito Intenso \\
\hline
\end{tabular}

\subsection{Fez comentários irônicos em tom de deboche}

Assinale a questão, conforme o grau de intensidade do que aconteceu com você, sendo 1 (pouco intenso) e 10 (muito intenso). Caso não tenha vivenciado o que consta na alternativa, marque 0 .

\begin{tabular}{|c|c|c|c|c|c|c|c|c|c|c|c|c|}
\hline & 0 & 1 & 2 & 3 & 4 & 5 & 6 & 7 & 8 & 9 & 10 & \\
\hline Não ocorreu & $\mathrm{E}$ & $E$ & 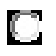 & 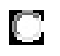 & $E$ & 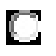 & $E$ & 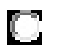 & $B$ & $\mathrm{E}$ & $\mathrm{E}$ & Muito Intenso \\
\hline
\end{tabular}

3.6 Chamou você por algum apelido desagradável

Assinale a questão, conforme o grau de intensidade do que aconteceu com você, sendo 1 (pouco intenso) e 10 (muito intenso). Caso não tenha vivenciado o que consta na alternativa, marque 0 .

\begin{tabular}{|l|r|r|r|r|r|r|r|r|r|r|r|l|}
\hline & 0 & 1 & 2 & 3 & 4 & 5 & 6 & 7 & 8 & 9 & 10 & \\
\hline \multirow{2}{*}{ Não ocorreu } & $\mathbf{C}$ & $\mathbf{C}$ & $\mathbf{C}$ & $\mathbf{C}$ & $\mathbf{C}$ & $\mathbf{C}$ & $\mathbf{C}$ & $\mathbf{C}$ & $\mathbf{C}$ & $\mathbf{C}$ & $\mathbf{C}$ & Muito Intenso \\
\hline
\end{tabular}

\subsection{Impediu a presença de acompanhante}

Assinale a questão, conforme o grau de intensidade do que aconteceu com você, sendo 1 (pouco intenso) e 10 (muito intenso). Caso não tenha vivenciado o que consta na alternativa, marque 0 .

\begin{tabular}{|c|c|c|c|c|c|c|c|c|c|c|c|c|}
\hline & 0 & 1 & 2 & 3 & 4 & 5 & 6 & 7 & 8 & 9 & 10 & \\
\hline Não ocorreu & 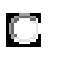 & $E$ & $G$ & C & $G$ & $\mathbb{G}$ & $G$ & $G$ & 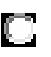 & $C$ & $B$ & Muito Intenso \\
\hline
\end{tabular}

\subsection{Outro. Qual?}

\section{Durante a internação hospitalar para ter o seu bebê ou no atendimento domiciliar por equipe de saúde, O QUÃO INTENSOS FORAM ESTES SENTIMENTOS:}

4. Sentiu-se pouco a vontade para fazer perguntas, porque não te respondiam ou te respondiam mal Assinale a questão, conforme o grau de intensidade do que aconteceu com você, sendo 1 (pouco intenso) e 10 (muito intenso). Caso não tenha vivenciado o que consta na alternativa, marque 0 .

\begin{tabular}{|l|c|c|c|c|c|c|c|c|c|c|c|c|}
\hline & 0 & 1 & 2 & 3 & 4 & 5 & 6 & 7 & 8 & 9 & 10 & \\
\hline Não ocorreu & $\mathbf{C}$ & $\mathbf{C}$ & $\mathbf{C}$ & $\mathbf{C}$ & $\mathbf{C}$ & $\mathbf{C}$ & $\mathbf{C}$ & $\mathbf{C}$ & $\mathbf{C}$ & $\mathbf{C}$ & $\mathbf{C}$ & Muito Intenso \\
\hline
\end{tabular}

\subsection{Sentiu-se ameaçada pela atitude ou fala de algum profissional}

Assinale a questão, conforme o grau de intensidade do que aconteceu com você, sendo 1 (pouco intenso) e 10 (muito intenso). Caso não tenha vivenciado o que consta na alternativa, marque 0 .

\begin{tabular}{|l|c|c|c|c|c|c|c|c|c|c|c|c|}
\hline & 0 & 1 & 2 & 3 & 4 & 5 & 6 & 7 & 8 & 9 & 10 & \\
\hline \multirow{2}{*}{ Não ocorreu } & $\mathbf{C}$ & $\mathbb{C}$ & $\mathbf{C}$ & $\mathbf{C}$ & $\mathbf{C}$ & $\mathbf{C}$ & $\mathbf{C}$ & $\mathbb{C}$ & $\mathbf{C}$ & $\mathbf{C}$ & $\mathbf{C}$ & Muito Intenso \\
\hline
\end{tabular}


4.2 Sentiu-se inferior, vulnerável, insegura

Assinale a questão, conforme o grau de intensidade do que aconteceu com você, sendo 1 (pouco intenso) e 10 (muito intenso). Caso não tenha vivenciado o que consta na alternativa, marque 0 .

\begin{tabular}{|l|r|r|r|r|r|r|r|r|r|r|r|r|}
\hline & 0 & 1 & 2 & 3 & 4 & 5 & 6 & 7 & 8 & 9 & 10 & \\
\hline Não ocorreu & $\boldsymbol{C}$ & $\boldsymbol{C}$ & $\boldsymbol{C}$ & $\boldsymbol{C}$ & $\boldsymbol{C}$ & $\boldsymbol{C}$ & $\boldsymbol{C}$ & $\boldsymbol{C}$ & $\boldsymbol{C}$ & $\boldsymbol{C}$ & $\boldsymbol{C}$ & Muito Intenso \\
\hline
\end{tabular}

\subsection{Sentiu-se exposta ou sem privacidade}

Assinale a questão, conforme o grau de intensidade do que aconteceu com você, sendo 1 (pouco intenso) e 10 (muito intenso). Caso não tenha vivenciado o que consta na alternativa, marque 0 .

\begin{tabular}{|l|r|r|r|r|r|r|r|r|r|r|r|r|}
\hline \multirow{2}{*}{ Não ocorreu } & 0 & 1 & 2 & 3 & 4 & 5 & 6 & 7 & 8 & 9 & 10 & \\
& $\boldsymbol{C}$ & $\boldsymbol{C}$ & $\boldsymbol{C}$ & $\boldsymbol{C}$ & $\boldsymbol{C}$ & $\boldsymbol{C}$ & $\boldsymbol{C}$ & $\boldsymbol{C}$ & $\boldsymbol{C}$ & $\boldsymbol{C}$ & $\boldsymbol{C}$ & Muito Intenso \\
\hline
\end{tabular}

\subsection{Outro. Qual?}

[Clique aqui se você entrou em trabalho de parto

C Clique aqui se você NÃO entrou em trabalho de parto e fez cesárea

5. Durante o TRABALHO DE PARTO, você:

Marque APENAS o que ocorreu com você

Foi impossibilitada de caminhar

- Foi impossibilitada de procurar posições mais confortáveis segundo as suas necessidades

6. Durante o trabalho de parto e parto foram realizados os seguintes procedimentos médicos SEM QUE TENHAM PEDIDO SEU CONSENTIMENTO OU EXPLICADO POR QUE ERAM NECESSÁRIOS?

Marque APENAS o que ocorreu com você

E Enema (lavagem intestinal)

- Tricotomia (raspagem de pelos)

- Uso de ocitocina ("soro" para acelerar o trabalho de parto)

- Toques vaginais repetitivos

- Toques vaginais realizados por diferentes pessoas

- Proibição para ingerir alimentos ou bebidas

- Rompimento artificial da bolsa (profissional rompeu/estourou sua bolsa)

- Apertaram ou subiram na sua barriga para "ajudar" o bebê a nascer

— Episiotomia (corte no períneo, "pique lá embaixo")

Г Cesárea

Г Corte imediato do cordão umbilical

\subsection{Outros. Quais?}

7. Durante o PERÍODO "EXPULSIVO", ou seja, no momento de fazer força para o bebê nascer, você: Marque APENAS o que ocorreu com você

- Foi privada da possibilidade de adotar a postura mais confortável para você realizar os puxos (fazer força)

— Teve "puxos dirigidos" pelo profissional de saúde, ou seja, ele dizia a frequência e o modo como você devia fazer força, sem respeitar seu ritmo

8. Relembrando sua CESÁREA, marque APENAS as situações que aconteceram com você:

Г Começar a cortar seu abdômen, sem esperar a anestesia "fazer efeito"

- Apertar ou subir na sua barriga para "ajudar" o bebê a nascer

- Conversas paralelas entre os profissionais sobre outros assuntos

Г Manter suas mãos amarradas, impedindo que tocasse seu bebê

Г Realização de procedimentos sem seu consentimento ou sem explicar por que eram necessários

\subsection{Outros. Quais?}


9. Relembrando o MOMENTO LOGO APÓS O NASCIMENTO, ainda na sala de parto/cesárea, antes dos primeiros cuidados com o bebê (pesar, medir, etc.), marque APENAS as situações que aconteceram com você:

- Teve o contato com seu bebê adiado, para que o profissional realizasse procedimentos desnecessários ou que poderiam esperar

- Teve seu bebê levado imediatamente para a sala de procedimentos, sem que nenhum profissional lhe explicasse o que estava acontecendo com ele

Г Foi forçada a amamentar ou estabelecer contato com o bebê (pegar no colo, olhar para o bebê, etc...) contra a sua vontade

Г Impediram ou dificultaram o aleitamento na $1^{\underline{a}}$ hora de vida do bebê, sem motivos para justificar esta atitude

De uma maneira geral, qual o seu grau de satisfação com o atendimento da equipe de saúde durante seu parto/cesárea?

Considere 1 (péssimo) e 10 (excelente).

\begin{tabular}{|l|r|r|r|r|r|r|r|r|r|r|r|}
\hline & 1 & 2 & 3 & 4 & 5 & 6 & 7 & 8 & 9 & 10 & \\
\hline \multirow{2}{*}{ Péssimo } & $\boldsymbol{C}$ & $\mathbf{C}$ & $\boldsymbol{C}$ & $\mathbf{C}$ & $\boldsymbol{C}$ & $\mathbf{C}$ & $\boldsymbol{C}$ & $\boldsymbol{C}$ & $\mathbf{C}$ & $\mathbf{C}$ & Excelente \\
\hline
\end{tabular}

Informações complementares

Caso exista alguma situação/acontecimento que você vivenciou em seu parto/cesárea e que não foi contemplado neste questionário, por favor, escreva aqui:

Caso queira participar da segunda etapa desta pesquisa ou ter acesso aos resultados, por favor, deixe seu e-mail de contato aqui: 